Research paper

\title{
Clinical impact of mitral calcium volume in patients undergoing transcatheter aortic valve implantation
}

\author{
Taishi Okuno $^{\text {a, }}{ }^{\text {, Nicolas Brugger }}{ }^{\mathrm{a}, 1}$, Masahiko Asami ${ }^{\mathrm{a}}$, Dik Heg ${ }^{\mathrm{b}}$, George C.M. Siontis ${ }^{\mathrm{a}}$, \\ Mirjam G. Winkel ${ }^{a}$, Jonas Lanz ${ }^{a}$, Christoph Gräni ${ }^{a}$, Adrian Huber ${ }^{c}$, Stefan Stortecky ${ }^{a}$, \\ Isaac George $^{\mathrm{d}}$, Susheel Kodali ${ }^{\mathrm{d}}$, Thomas Pilgrim ${ }^{\mathrm{a}}$, Stephan Windecker ${ }^{\mathrm{a}}$, Omar K. Khalique ${ }^{\mathrm{d}, 2}$, \\ Fabien Praz ${ }^{\text {a, },}, 2$

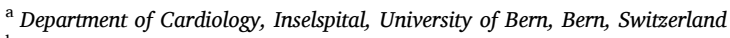 \\ ${ }^{\mathrm{b}}$ CTU, University of Bern, Bern, Switzerland \\ ${ }^{\mathrm{c}}$ Department of Diagnostic, Interventional and Pediatric Radiology, Inselspital, University of Bern, Bern, Switzerland \\ d Structural Heart and Valve Center, Division of Cardiology, New York-Presbyterian Hospital-Columbia University Medical Center, New York, USA
}

\section{A R T I C L E I N F O}

\section{Keywords:}

Aortic stenosis

Mitral annular calcification

Mitral regurgitation

Mitral stenosis

Transcatheter aortic valve implantation

Mitral valve

\begin{abstract}
A B S T R A C T
Background: Mitral annular calcification (MAC) has been associated with mitral valve (MV) disease and cardiovascular events in patients undergoing transcatheter aortic valve implantation (TAVI). We aimed to investigate the incidence and impact of mitral calcium volume (MCV) quantified by multidetector computed tomography (MDCT) on MV function and clinical outcomes after TAVI.

Methods: Consecutive patients with exploitable echocardiography and MDCT performed during TAVI screening were enrolled in this retrospective analysis. Mitral calcium was assessed visually and measured using a semiautomatic tool developed for the aortic valve in an off-label fashion.

Results: MCV $>0 \mathrm{~mm}^{3}$ was found in $65 \%$ of the 875 included patients. Patients with calcification were older ( 82 \pm 6 versus $81 \pm 7 ; \mathrm{P}=0.002)$ and had high prevalence of renal dysfunction $(69 \%$ versus $61 \% ; \mathrm{P}=0.017)$ and mitral stenosis $(25 \%$ versus $4 \%, \mathrm{P}<0.001)$. MCV correlated well with visual MAC severity $(\mathrm{r}=0.94 ; \mathrm{P}<0.001)$, but showed a greater predictive value for mitral stenosis ( $A U C=0.804$ vs. $0.780, P=0.012$ ), while it was not a predictor of mitral regurgitation (AUC $=0.514$ ). Correlations were found between MCV and echocardiographic parameters including MV area, mean transmitral gradient, and pressure half-time $(\mathrm{P}<0.001$ for all). MCV did not impact on cardiovascular mortality or new permanent pacemaker implantation after TAVI.

Conclusions: Calcification of the mitral apparatus is common in TAVI candidates and results in mitral stenosis in $25 \%$ of the patients. Increasing MCV predicts mitral stenosis, but had no impact on clinical outcomes following TAVI.

Clinical trial registration: NCT01368250.
\end{abstract}

\section{Introduction}

Mitral annular calcification (MAC) is a degenerative change of the fibrous atrio-ventricular junction ${ }^{1}$ that can occasionally involve the mitral valve (MV) leaflets and the subvalvular apparatus. The prevalence of MAC ranges from 8 to $15 \%$ in the general population, and increases with age, cardiovascular risk factors, and chronic kidney disease (CKD) suggesting a link to atherosclerosis. ${ }^{1-3}$ MAC is a predictor of cardiovascular events and mortality in the general population. ${ }^{4-6}$ MAC of any severity has been observed in about half of transcatheter aortic valve implantation (TAVI) candidates and has been associated with increased mortality when visually severe, ${ }^{7,8}$ possibly because of its frequent association with MV dysfunction. ${ }^{9}$

Multidetector computed tomography (MDCT) is now considered the gold standard for the detection of cardiac calcification., ${ }^{2,7-13}$ Although frequently applied to the aortic valve, ${ }^{14-17}$ quantitative assessment of mitral calcium volume (MCV) has not been well studied and MAC as a

\footnotetext{
* Corresponding author. Department of cardiology Inselspital, University of Bern, CH-3010, Bern, Switzerland.

E-mail address: fabien.praz@insel.ch (F. Praz).

1 Dr. Okuno and Dr. Brugger contributed equally to this work and are joint first authors.

${ }^{2}$ Dr. Khalique and Dr. Praz contributed equally to this work and are joint senior authors.
} 

Abbreviation and acronyms
CKD chronic kidney disease
LVOT left ventricular outflow tract
MAC Mitral annular calcification
MCV mitral calcium volume
MDCT multidetector computed tomography
MR mitral regurgitation
MS mitral stenosis
MV mitral valve
MVA mitral valve area
PPI permanent pacemaker implantation
TAVI transcatheter aortic valve implantation

disease has been poorly described. We assess the impact of MAC quantified by MCV on MV function and clinical outcomes after TAVI.

\section{Methods}

\subsection{Study population}

The Bern TAVI registry is a prospective institutional registry that is a part of the nationwide Swiss TAVI registry (NCT01368250). ${ }^{18}$ Patients undergoing TAVI between August 2007 and December 2016 at Bern University Hospital, Bern, Switzerland were consecutively enrolled. For the present analysis, patients with sufficient echocardiography and MDCT data for detailed assessment of MV function and MCV were included. Patients treated with a non-CE marked device, as well as those who did not receive any transcatheter heart valve or had a previous mitral valve intervention were excluded. The registry was approved by

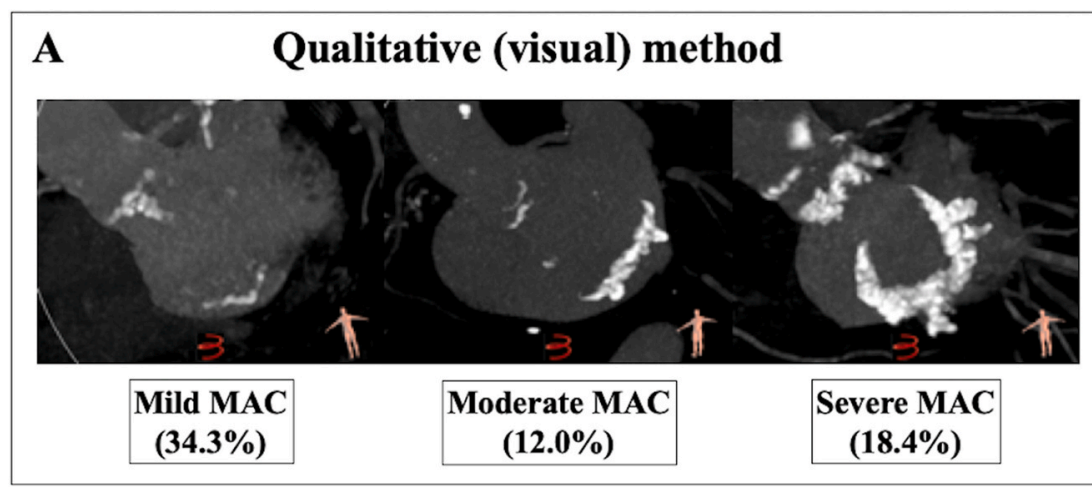

\section{B Quantitative volumetric method (MCV)}

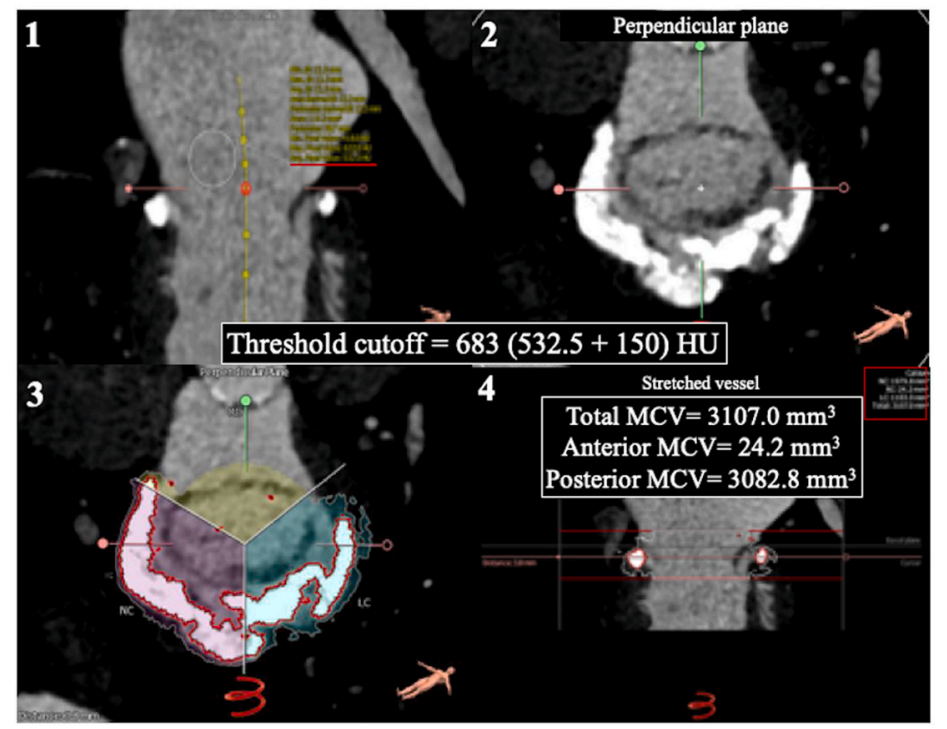

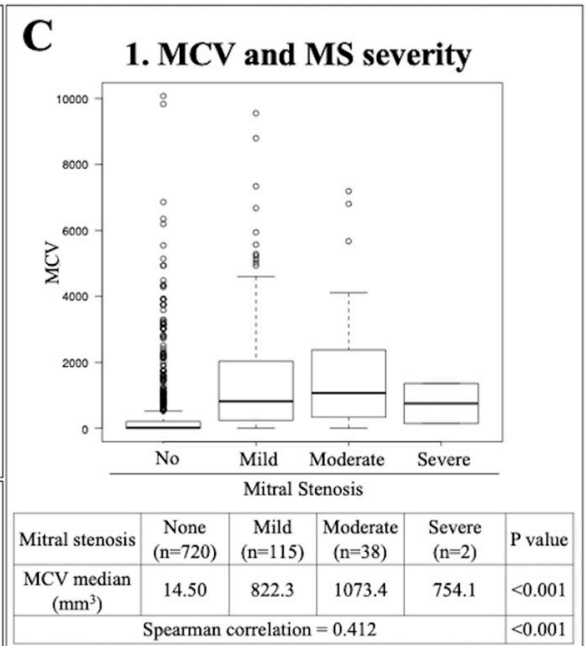

2. ROC for the presence of MS

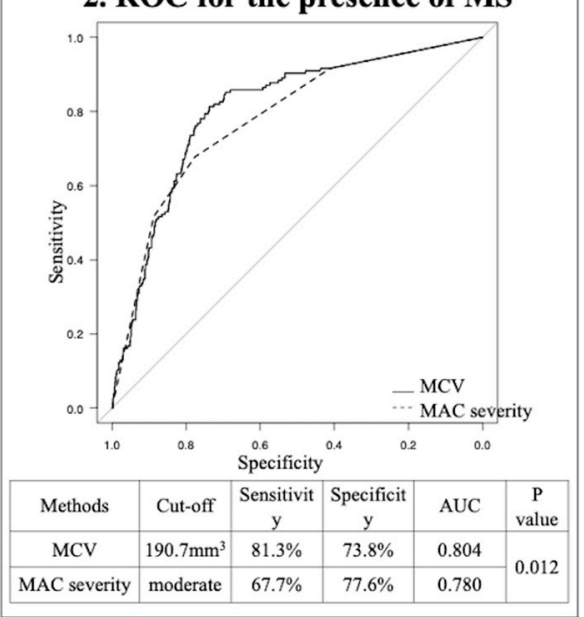

Fig. 1. Principles of qualitative and quantitative mitral calcium assessment and clinical implications.

(A) The qualitative (visual) method: MAC severity was determined according to the visual circumferential involvement of the mitral annulus (mild: less than $1 / 3$ of the annulus, moderate: between $1 / 3$ and $1 / 2$ of the annulus, severe: more than half of the annulus). (B) The quantitative volumetric method (MCV): (1) Curved multiplanar reconstruction analyses were manually performed using the aortic module in an off-label fashion, with a line generated through the center-point of the left atrium, mitral annular plane, and left ventricle. Average luminal attenuation in Hounsfield Units (HU) was measured in the left atrium using a pixel probe tool, and a threshold cut-off for the detection of calcium was set as the average luminal attenuation (the value underlined by red) plus $150 \mathrm{HU}(=683 \mathrm{HU})$. (2, 4) The region of interest for MCV quantification was carefully identified by using both perpendicular plane view and stretched vessel view. (3) Total MCV was subdivided according to location (anterior or posterior). (C-1) MCV significantly differs according to echocardiographic MS severity (Kruskal-Wallis test $\mathrm{p}<0.001$ ), and had a moderate but significant correlation with MS severity $(r=0.412, \mathrm{P}<0.001)$. (C-2) Predictive value of MCV (AUC: $0.804,95 \%$ CI: $0.767-0.842)$ and visual MAC severity (AUC: $0.780,95 \%$ CI: 0.741-0.819) for the presence of MS. MCV had a significantly greater predictive value compared with visual MAC severity. MAC: mitral annular calcification; MCV; mitral calcium volume; MS: mitral stenosis; AUC: area under the curve; ROC: receiver operating curve. (For interpretation of the references to colour in this figure legend, the reader is referred to the Web version of this article.) 


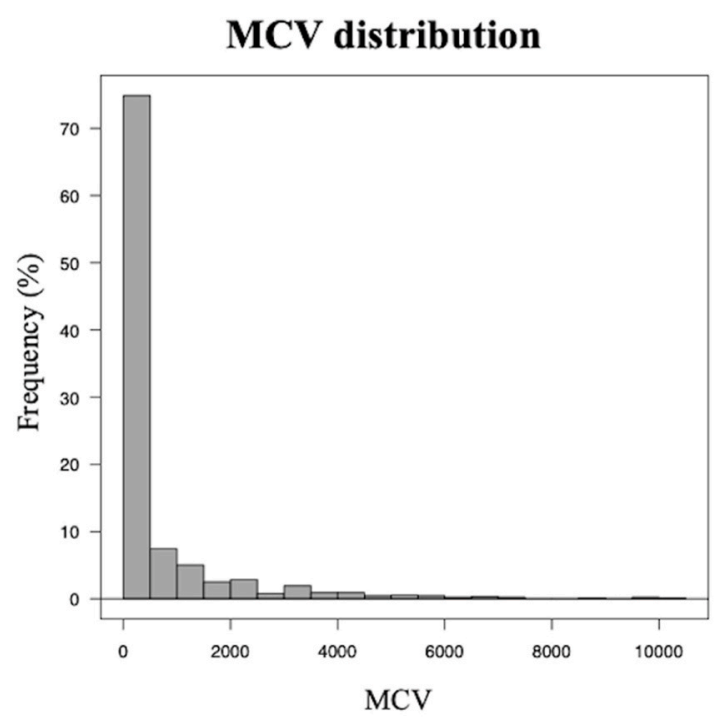

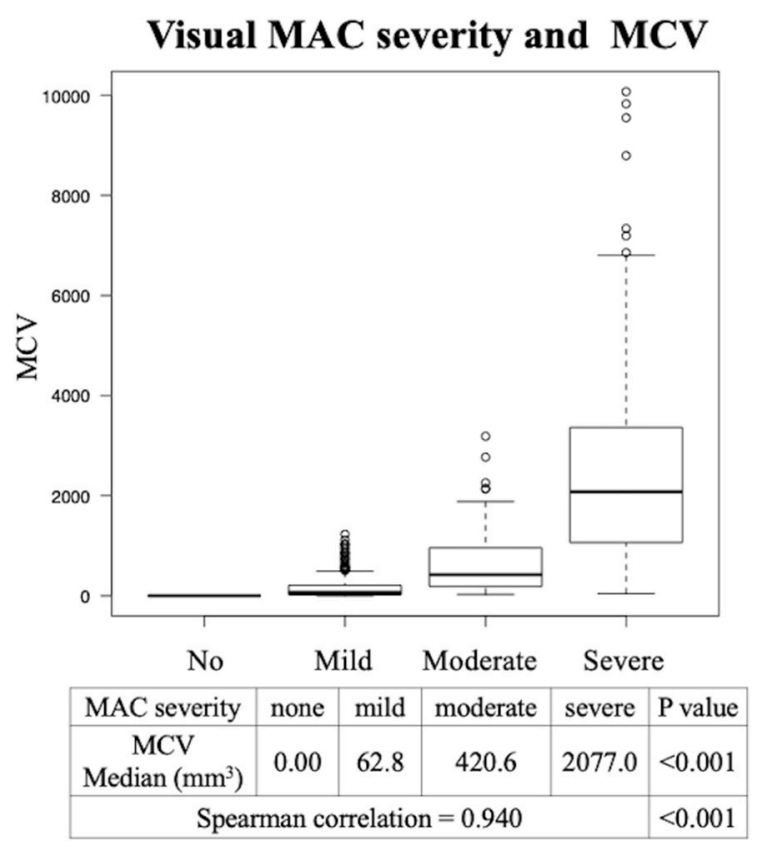

Fig. 2. Distribution of MCV and the association with visual MAC severity. MCV distribution is shown using ranges of $500 \mathrm{~mm}^{3}$. There was a robust correlation with visual MAC severity. MCV: mitral calcium volume; MAC: mitral annular calcification.

the local ethics committee, and patients provided written informed consent.

\subsection{Assessment of mitral calcium}

Details of the MDCT scanning protocols used consecutively during the study period are provided as a Supplemental Table. The obtained studies were transferred to a dedicated workstation for off-line analysis using the 3mensio Structural Heart software (3mensio Medical Imaging BV, Bilthoven, The Netherlands). Calcification of the mitral apparatus was assessed using two different methods: the conventional visual assessment and the new quantitative volumetric method. The detail of the conventional method has previously been described. ${ }^{9}$ Briefly, MAC severity was determined according to the visual circumferential involvement of the mitral annulus as follows: mild $=$ less than $1 / 3$ of the annulus involved; moderate $=$ between $1 / 3$ and $1 / 2$; and severe $=$ more than half of the mitral annulus circumference (Fig. 1; panel A). For the quantitative method, the MV was identified manually using the aortic module in an off-label fashion. A centerline was generated through the left atrium, mitral annular plane, and left ventricle. The average luminal attenuation in Hounsfield Units (HU) was measured in the left atrium using a pixel probe tool (Fig. 1; panel B1). The individual cut-off for calcium detection was defined as the average luminal attenuation plus $150 \mathrm{HU}$ to ensure correct discrimination between contrasted blood and calcium deposits. The region of interest was manually adjusted using two planes: a short axis view of the mitral annulus and a stretched view (Fig. 1; panels B2-4). Aortic as well as left ventricular outflow tract (LVOT) calcium were carefully excluded from the analysis. For the distinction between confluent mitral and LVOT calcification, a short axis view centered on the mitral apparatus was used. Calcium deposits located on the aortic side of the intertrigonal line were regarded as belonging to the LVOT and excluded from the analysis (Supplemental Fig. 1). Total MCV was calculated automatically and further subdivided into anterior and posterior MCV after identification of the commissure as shown in Fig. 1 (panel B3). Intra-observer and inter-observer reliability of MCV were tested in a subset of 20 randomly selected patients with $\mathrm{MCV}>0 \mathrm{~mm}^{3}$.

\subsection{Assessment of mitral valve function}

MV dysfunction was graded as mild, moderate, and severe according to integrative criteria as described by current guidelines ${ }^{19,20}$ using preoperative transthoracic echocardiography. For mitral stenosis (MS) grading, mean gradient (mild $<5 \mathrm{mmHg}$, moderate $5-10 \mathrm{mmHg}$, and severe $>10 \mathrm{mmHg}$ ) and valve area (mild $>1.5 \mathrm{~cm}^{2}$, moderate $1.0-1.5$ $\mathrm{cm}^{2}$, and severe $<1.0 \mathrm{~cm}^{2}$ ) were considered. The mitral valve area (MVA) was calculated using pressure half-time, and planimetry when available. A vena contracta width of $\geq 7 \mathrm{~mm}$, an effective regurgitant orifice area according to the proximal isovelocity surface area method (EROA PISA) $\geq 40 \mathrm{~mm} 2$ and/or a regurgitation volume $\geq 60 \mathrm{ml}$, as well as the documentation of systolic pulmonary flow reversal were indicative of severe mitral regurgitation (MR). Grading of MR and MS severity was performed by an independent imaging specialist (N. B.) blinded to the MDCT findings.

\subsection{Clinical outcomes}

Clinical follow-up data at 30 days, 1 year, and 5 years were obtained by standardized interviews, documentation from referring physicians, and hospital discharge summaries. All adverse events up to 1 year were adjudicated by a dedicated clinical event committee according to the Valve Academic Research Consortium (VARC-2) criteria, ${ }^{21}$ while the events between 1 year and 5 years were not completely adjudicated.

\subsection{Statistical analysis}

Categorical data are represented as frequencies and percentages and the differences between groups are evaluated with the Chi-square test or Fisher exact test. Continuous variables are expressed as mean values \pm standard deviation (SD) and compared using Student's $t$-test. MCV is expressed as median values and interquartile ranges (IQR) and compared using Kruskal-Wallis test. Spearman rank correlation coefficients were used to measure associations between variables. Intraclass correlation coefficients (ICC) were calculated for intra-observer and inter-observer variation (individual rating, absolute agreement ICCs). Receiver operating characteristics (ROC) curves were used to 
Table 1

Baseline characteristics according to the presence or absence of mitral valve calcium.

\begin{tabular}{|c|c|c|c|c|}
\hline & $\begin{array}{l}\text { All }(n= \\
875)\end{array}$ & $\begin{array}{l}\mathrm{MCV}=0 \mathrm{~mm}^{3} \\
(\mathrm{n}=309)\end{array}$ & $\begin{array}{l}\mathrm{MCV}>0 \mathrm{~mm}^{3} \\
(\mathrm{n}=566)\end{array}$ & p-value \\
\hline Age (years) & $81.9 \pm 6.3$ & $81.0 \pm 7.1$ & $82.4 \pm 5.9$ & 0.002 \\
\hline Gender (female) & $\begin{array}{l}459 \\
(52.5 \%)\end{array}$ & $149(48.2 \%)$ & $310(54.8 \%)$ & 0.066 \\
\hline STS PROM & $\begin{array}{l}5.39 \pm \\
3.62\end{array}$ & $5.19 \pm 3.35$ & $5.50 \pm 3.77$ & 0.229 \\
\hline $\begin{array}{l}\text { Degenerative } \\
\text { bioprosthetic valve }\end{array}$ & $24(2.7 \%)$ & $14(4.5 \%)$ & $10(1.8 \%)$ & 0.028 \\
\hline Hypertension & $\begin{array}{l}726 \\
(83.0 \%)\end{array}$ & $258(83.5 \%)$ & $468(82.7 \%)$ & 0.779 \\
\hline Diabetes mellitus & $\begin{array}{l}205 \\
(23.4 \%)\end{array}$ & $67(21.7 \%)$ & $138(24.4 \%)$ & 0.404 \\
\hline Dyslipidemia & $\begin{array}{l}563 \\
(64.3 \%)\end{array}$ & $204(66.0 \%)$ & $359(63.4 \%)$ & 0.461 \\
\hline CKD (GFR< <6) & $\begin{array}{l}581 \\
(66.4 \%)\end{array}$ & $189(61.2 \%)$ & $392(69.3 \%)$ & 0.017 \\
\hline \multicolumn{5}{|c|}{ Electrocardiographic parameters } \\
\hline Atrial fibrillation & $\begin{array}{l}225 \\
(25.7 \%)\end{array}$ & $73(23.6 \%)$ & $152(26.9 \%)$ & 0.332 \\
\hline LBBB & $94(11.7 \%)$ & $30(10.8 \%)$ & $64(12.2 \%)$ & 0.645 \\
\hline RBBB & $70(8.7 \%)$ & $28(10.1 \%)$ & $42(8.0 \%)$ & 0.358 \\
\hline \multicolumn{5}{|c|}{ Echocardiographic Parameters } \\
\hline $\operatorname{AVA}\left(\mathrm{cm}^{2}\right)$ & $\begin{array}{l}0.66 \pm \\
0.25\end{array}$ & $0.69 \pm 0.27$ & $0.65 \pm 0.24$ & 0.025 \\
\hline LVEF (\%) & $\begin{array}{l}55.0 \pm \\
14.4\end{array}$ & $53.0 \pm 15.9$ & $56.0 \pm 13.5$ & 0.003 \\
\hline AR $(\geq$ moderate $)$ & $93(10.6 \%)$ & $46(15.1 \%)$ & $47(8.4 \%)$ & 0.004 \\
\hline MR ( $\geq$ moderate $)$ & $\begin{array}{l}151 \\
(17.3 \%)\end{array}$ & $59(19.1 \%)$ & $92(16.3 \%)$ & 0.304 \\
\hline TR $(\geq$ moderate $)$ & $\begin{array}{l}115 \\
(13.2 \%)\end{array}$ & $38(12.3 \%)$ & $77(13.6 \%)$ & 0.602 \\
\hline $\begin{array}{l}\text { Mitral Stenosis } \\
\text { None }\end{array}$ & $\begin{array}{l}\mathrm{n}=875 \\
721 \\
(82.4 \%)\end{array}$ & $\begin{array}{l}\mathrm{n}=309 \\
296(95.8 \%)\end{array}$ & $\begin{array}{l}n=566 \\
425(75.1 \%)\end{array}$ & $\begin{array}{l}<0.001 \\
<0.001\end{array}$ \\
\hline Mild & $\begin{array}{l}114 \\
(13.0 \%)\end{array}$ & $10(3.2 \%)$ & $104(18.4 \%)$ & $<0.001$ \\
\hline Moderate & $38(4.3 \%)$ & $3(1.0 \%)$ & $35(6.2 \%)$ & $<0.001$ \\
\hline Severe & $2(0.2 \%)$ & $0(0.0 \%)$ & $2(0.4 \%)$ & 0.543 \\
\hline $\begin{array}{l}\text { Mitral Stenosis } \\
\text { Etiology }\end{array}$ & $(n=154)$ & $(n=13)$ & $(\mathrm{n}=141)$ & 0.386 \\
\hline Rheumatic & $69(44.8 \%)$ & $4(30.8 \%)$ & $65(46.1 \%)$ & \\
\hline Degenerative & $85(55.2 \%)$ & $9(69.2 \%)$ & $76(53.9 \%)$ & \\
\hline $\begin{array}{l}\text { Mitral mean gradient } \\
\quad(\mathrm{mmHg})\end{array}$ & $\begin{array}{l}2.03 \pm \\
1.66\end{array}$ & $1.25 \pm 0.85$ & $2.42 \pm 1.83$ & $<0.001$ \\
\hline $\begin{array}{l}\text { Mitral pressure half- } \\
\text { time (msec) }\end{array}$ & $\begin{array}{l}70.12 \pm \\
30.34\end{array}$ & $63.54 \pm 27.36$ & $\begin{array}{l}73.65 \pm \\
31.29\end{array}$ & $<0.001$ \\
\hline $\begin{array}{l}\text { Mitral valve area } \\
\left(\mathrm{cm}^{2}\right)\end{array}$ & $\begin{array}{l}3.86 \pm \\
1.39\end{array}$ & $4.08 \pm 1.40$ & $3.73 \pm 1.37$ & 0.001 \\
\hline PASP (mmHg) & $\begin{array}{l}46.00 \pm \\
14.74\end{array}$ & $46.25 \pm 16.09$ & $\begin{array}{l}45.88 \pm \\
14.04\end{array}$ & 0.801 \\
\hline \multicolumn{5}{|l|}{ MDCT measurement } \\
\hline Total MCV $\left(\mathrm{mm}^{3}\right)$ & $\begin{array}{l}40.6[0.0 \\
506.0]\end{array}$ & $0.0[0.0,0.0]$ & $\begin{array}{l}250.6[49.6, \\
1083.0]\end{array}$ & $<0.001$ \\
\hline Anterior MCV $\left(\mathrm{mm}^{3}\right)$ & $\begin{array}{l}0.0[0.0, \\
18.9]\end{array}$ & $0.0[0.0,0.0]$ & $\begin{array}{l}6.8[0.1 \\
59.0]\end{array}$ & $<0.001$ \\
\hline Posterior MCV $\left(\mathrm{mm}^{3}\right)$ & $\begin{array}{l}29.6[0.0 \\
409.9]\end{array}$ & $0.0[0.0,0.0]$ & $\begin{array}{l}206.8[35.3 \\
996.8]\end{array}$ & $<0.001$ \\
\hline
\end{tabular}

MAC $=$ mitral annular calcification, STS PROM = Society of Thoracic Surgeons Predicted Risk Of Mortality, CKD = chronic kidney disease, AVA = aortic valve area, $\mathrm{LVEF}=$ left ventricular ejection fraction, $\mathrm{AR}=$ aortic regurgitation, $\mathrm{MR}=$ mitral regurgitation, $\mathrm{TR}=$ tricuspid regurgitation, $\mathrm{PASP}=$ pulmonary artery systolic pressure. LBBB: left bundle branch block; RBBB: right bundle branch block; MDCT: multidetector computed tomography; MCV: mitral calcium volume.

investigate the prognostic value of MCV detection and quantification. Univariate and multivariate logistic regression models were used to calculate odds ratios (OR) and 95\% confidence intervals (95\% CI) for the presence of MS; continuous variable of MCV was transformed into a binary variable using the cut-off with the highest sensitivity and specificity for MS prediction derived from the ROC analysis. Univariate Cox proportional hazard model was used to calculate crude hazard ratios (HR) and $95 \%$ CI. P-value of $<0.05$ was considered significant. Statistical analyses were performed using Stata version 15.1 (StataCorp, College Station, Texas) and EZR software (Saitama Medical Center, Jichi Medical University, Saitama, Japan) which is a graphical user interface for R (The R Foundation for Statistical Computing, Vienna, Austria).

\section{Results}

Among 1597 consecutive TAVI candidates, 722 patients were excluded due to insufficient echocardiographic or MDCT data for comprehensive assessment of MV function and MCV. Sufficient MDCT images for the calculation of MCV were not available in 341 patients, and echocardiographic images were incomplete or of insufficient quality for detailed assessment of MR in 70 patients and of MS in 460 patients. Therefore, 875 individuals were analysed in the present study.

Integrative echocardiographic assessment of the MV function identified 720 patients $(82.3 \%)$ without MS, 115 (13.1\%) with mild MS, 38 (4.3\%) with moderate MS and 2 patients $(0.2 \%)$ with severe MS. Key echocardiographic parameters for each category are shown in Online Fig. 1. Moderate or greater MR was diagnosed in 151 patients $(17.3 \%)$.

Any degree of mitral calcium (MCV $>0 \mathrm{~mm}^{3}$ ) was present in 566 patients (64.7\%): MCV was $<100 \mathrm{~mm}^{3}$ in $21.0 \%, 100$ to $<500$ in $18.5 \%$, 500 to $<1000$ in $7.4 \%$, and $\geq 1000$ in $17.7 \%$. According to visual assessment, mild MAC was present in $34.3 \%$, moderate MAC in $12.0 \%$, and severe MAC in $18.4 \%$. Distribution of MCV in the overall cohort and its association with the visual MAC severity are shown in Fig. 2. MCV was found to correlate well with MAC severity determined by visual assessment $(\mathrm{r}=0.940, \mathrm{P}<0.001)$. Both intra-observer and interobserver agreement were excellent (ICC 0.998, 95\%CI 0.994-0.999; ICC 0.996, 95\%CI 0.991-0.999; respectively).

Baseline and echocardiographic variables according to the presence or absence of mitral calcium are summarized in Table 1. Of note, the prevalence of MS ( $\geq$ mild) was significantly higher in patients with mitral calcium $(24.9 \%$ versus $4.2 \%, \mathrm{P}<0.001)$, whereas it was comparable for moderate or greater MR (16.3\% versus $19.1 \%, \mathrm{P}=0.304)$. No significant MV dysfunction (MS or MR) was observed in $62.7 \%$ of patients with $\mathrm{MCV}>0 \mathrm{~mm}^{3}$.

\subsection{Mitral calcium and mitral valve dysfunction}

The associations between MCV/visual MAC severity and MS is shown in Fig. 1 (Panel C) and Fig. 3. Both MCV (Fig. $1 \mathrm{C} 1 ; \mathrm{r}=0.412, \mathrm{P}<0.001$ ) and visual MAC severity (Fig. $3 \mathrm{~A} ; \mathrm{r}=0.387, \mathrm{P}<0.001$ ) had a moderate but statistically significant correlation with MS severity. ROC curve analyses for the presence of MS of any severity revealed a greater predictive value for MCV compared to visual MAC severity (Fig. 1 Panel C2. MCV: AUC 0.804, 95\%CI 0.767-0.842; Visual: AUC 0.780, 95\%CI $0.741-0.819 ; \mathrm{P}=0.012$ ). A cut-off of $190.7 \mathrm{~mm}^{3}$ was found to predict the presence of at least mild MS with a specificity of $74 \%$ and a sensitivity of $81 \%$, and a cut-off of $229.9 \mathrm{~mm}^{3}$ was found to predict the presence of moderate or greater MS with a specificity of specificity of $69 \%$ and a sensitivity of $85 \%$. The representative MAC images for the cut-off are shown in Online Fig. 2. There was a clear incremental diagnostic value associated with the use of the quantitative volumetric method for the category of patients with mild or moderate MAC (Fig. 3B-I and II).

As shown in Online Fig. 3, there were statistically significant correlations between key echocardiographic parameters and MCV (MVA: $\mathrm{r}=$ $-0.267, \mathrm{P}<0.001$; mitral mean gradient: $\mathrm{r}=0.527, \mathrm{P}<0.001$; pressure half-time: $\mathrm{r}=0.242, \mathrm{P}<0.001)$. Whereas almost all patients with relevant MS had calcium deposit, half of the patients with visually severe MAC had no significant MS. Among the 37 patients with moderate or severe MS, all had calcification extending to the mid-portion of the leaflets, and 19 (51\%) even to the tip.

In contrast, there was no correlation between MCV and MR severity 


\section{A. MS severity and visual MAC severity}

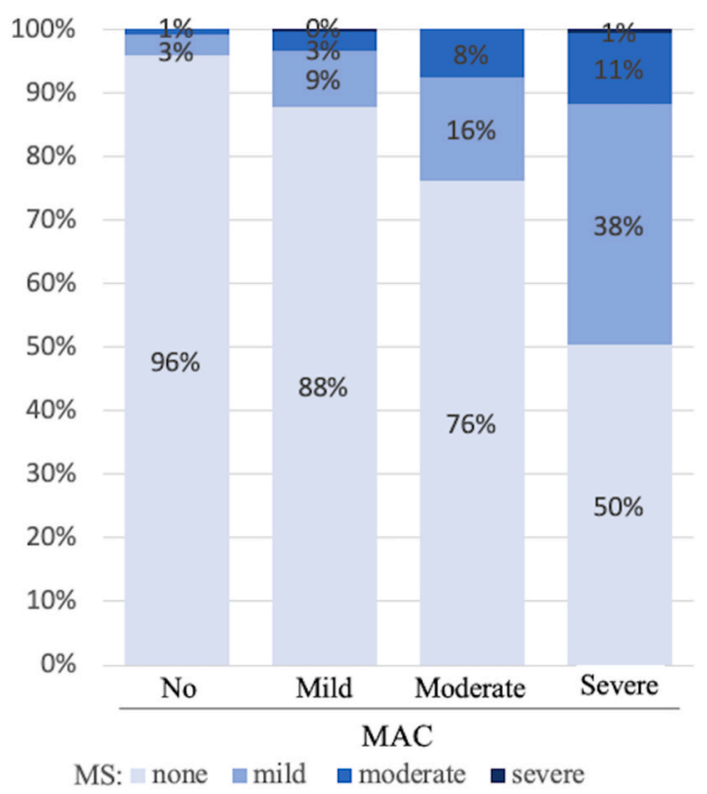

The spearman correlation coefficient $=0.387,(\mathrm{P}<0.001)$

\section{B. Additional diagnostic value of MCV for the presence of MS}

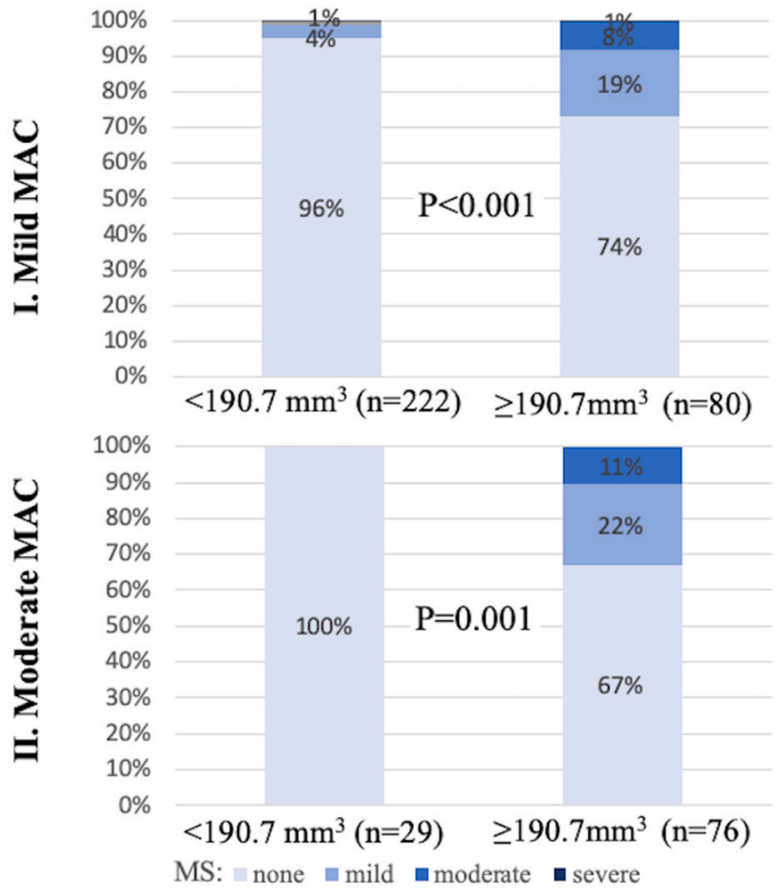

Fig. 3. Association of mitral calcium and mitral stenosis.

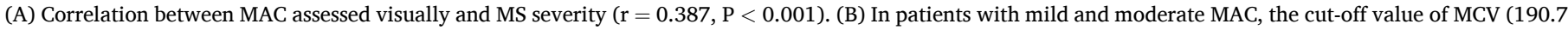

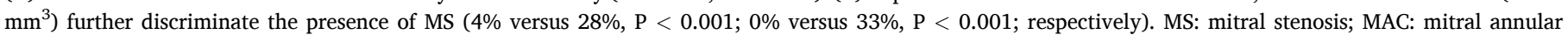
calcification; MCV: mitral calcium volume.

(Online Fig. 4A. $\mathrm{r}=0.028, \mathrm{P}=0.417$ ), and MCV was not predictive of the presence of moderate or greater MR (Online Fig. 4B; AUC $=0.514$, $95 \% \mathrm{CI}=0.461-0.567)$.

\subsection{Impact of mitral calcium distribution}

Mitral calcium was located only posteriorly in $23.3 \%$, only anteriorly in $3.7 \%$, and on both aspects of the MV in $73.0 \%$. Both anterior and posterior MCV had significant correlations with MS severity (Online Fig. 5A and B). Posterior MCV was a stronger predictor of MS ( $\geq$ mild) compared to anterior MCV (Posterior MCV: AUC $=0.806$, 95\% $\mathrm{CI}=$ 0.769-0.843; Anterior MCV: AUC $=0.711,95 \% \mathrm{CI}=0.665-0.758$; $\mathrm{P}<$ 0.001 ) (Fig. 4). The presence of anterior MCV was significantly associated with higher total MCV $\left(341.8[84.9,1344.9] \mathrm{mm}^{3}\right.$ versus 85.6 $\left.[21.6,437.9] \mathrm{mm}^{3}, \mathrm{P}<0.001\right)$.

\subsection{Predictors of mitral stenosis}

Uni- and multivariable logistic regression analysis was performed to identify independent predictors of MS (Table 2). Both anterior and posterior MCV independently predicted the presence of MS of any severity (Table 2. Adjusted OR 2.95, 95\%CI 1.91-4.55, P < 0.001; Adjusted OR 8.11, 95\%CI 5.11-12.90, P $<0.001$; respectively).

\subsection{Mitral calcium and clinical outcomes}

Clinical outcomes up to 5 years are shown in Table 3. There was no effect of MCV on clinical outcomes including mortality, myocardial infarction, disabling stroke, and new permanent pacemaker implantation (PPI). Further evaluation using quartiles of MCV, also failed to unmask any effect of mitral calcium on cardiovascular death up to 5 years and new PPI following TAVI at 30 days (Table 4). A sensitivity analysis excluding patients with baseline permanent pacemaker, cardioverter-defibrillator, right bundle branch block, or atrioventricular block showed consistent results (Table 4).

\section{Discussion}

The salient findings of the present study can be summarized as follows: 1) Calcification of the mitral apparatus is common in TAVI candidates (64.7\%), and results in MS in $25 \%$ of the patients; 2 ) Both the visual and the quantitative assessment of mitral calcium predict the presence of MS but not MR. 3) The use of quantitative MCV confers an incremental diagnostic value - a cut-off of $190.7 \mathrm{~mm}^{3}$ was found to predict the presence of MS ( $\geq$ mild) with a specificity of $74 \%$ and a sensitivity of $81 \%$. Posterior MCV best predicted the presence of MS. 4) However, MCV did not affect clinical outcomes after TAVI, including cardiovascular death and new PPI.

Several studies have investigated the relationship between MAC and cardiovascular events, as well as MV disease. ${ }^{1}$ Conventional surgical repair in patients with MAC is associated with an increased risk of bleeding, paravalvular leak, injury to the left circumflex artery, and rupture of the atrioventricular grove, as well as debris embolization. Thus, concentric MAC has recently become a target for alternative minimally-invasive techniques including transatrial ${ }^{22}$ or transfemoral/transseptal implantation of a TAVI valve, ${ }^{23}$ as well as transcatheter mitral valve replacement. ${ }^{24}$ Notwithstanding, little is known about the disease itself, as well as the mechanisms of MV dysfunction in the presence of MAC.

MDCT is considered the gold standard for the assessment of mitral valve calcium due to the low specificity of echocardiography for the distinction between calcification and dense collagen. ${ }^{2,3,7-9,11}$ However, visual assessment (circumferential involvement of the mitral ring) yielded conflicting results. ${ }^{7-9}$ In a cohort of 761 patients undergoing 


\section{ROC for the presence of MS (Anterior MCV and Posterior MCV)}

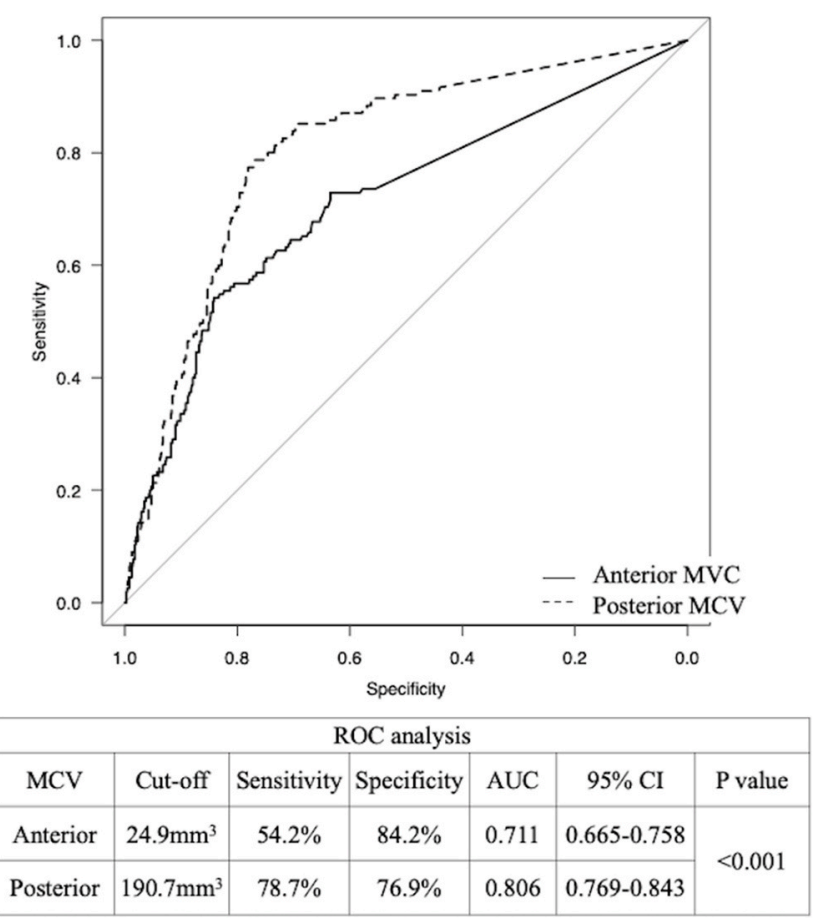

Fig. 4. Impact of calcium distribution for the prediction of mitral stenosis. Posterior MCV volume was the strongest predictor of the presence of MS (posterior MCV versus anterior MCV: AUC $=0.806$ versus 0.711, $\mathrm{P}<0.001$ ). ROC: receiver operating curve; MS: mitral stenosis; MCV: mitral calcium volume; AUC: area under the curve; CI: confidence interval.

TAVI, severe MAC was associated with increased all-cause and cardiovascular death, as well as conduction abnormalities following TAVI. ${ }^{7}$ In contrast, our previous work suggested that severe MAC alone was not associated with mortality after TAVI but rather concomitant valve dysfunction. ${ }^{9}$ This discrepancy may partially be explained by the inaccuracy of the visual assessment. The method has the important disadvantage to disregard the longitudinal extension of the calcium and thus, represents in some cases a rather imprecise estimate of the actual calcium burden as illustrated in Fig. 5. Calculation of the mitral Agatston score ${ }^{12,13,25}$ has been described as an alternative. Recently, researchers suggested that quantitative MAC scoring by the Agatston method is more reliable than visual assessment and has high accuracy to diagnose
Table 3

Clinical outcomes according to mitral calcium volume.

\begin{tabular}{|c|c|c|c|c|}
\hline & $\begin{array}{l}\mathrm{MCV}=0 \\
\mathrm{~mm}^{3}(\mathrm{n}= \\
309)\end{array}$ & $\begin{array}{l}\mathrm{MCV}>0 \mathrm{~mm}^{3} \\
(\mathrm{n}=566)\end{array}$ & HR $(95 \% \mathrm{CI})$ & $\begin{array}{l}P \\
\text { value }\end{array}$ \\
\hline \multicolumn{5}{|l|}{ At 30 days $^{\mathrm{a}}$} \\
\hline $\begin{array}{l}\text { All-cause death (n, } \\
\% \text { ) }\end{array}$ & $13(4.2)$ & $17(3.0)$ & $\begin{array}{l}0.71 \\
(0.34-1.45)\end{array}$ & 0.346 \\
\hline CV-death (n, \%) & $11(3.6)$ & $15(2.7)$ & $\begin{array}{l}0.74 \\
(0.34-1.61)\end{array}$ & 0.443 \\
\hline $\begin{array}{l}\text { Myocardial } \\
\text { infarction (n, \%) }\end{array}$ & $6(2.0)$ & $5(0.9)$ & $\begin{array}{l}0.45 \\
(0.14-1.48)\end{array}$ & 0.191 \\
\hline $\begin{array}{l}\text { Disabling stroke } \\
(\mathrm{n}, \%)\end{array}$ & $6(2.0)$ & $15(2.7)$ & $\begin{array}{l}1.37 \\
(0.53-3.52)\end{array}$ & 0.519 \\
\hline $\begin{array}{l}\text { Kidney injury } \\
\text { stage } 3(\mathrm{n}, \%)\end{array}$ & $4(1.3)$ & $13(2.3)$ & $\begin{array}{l}1.77 \\
(0.58-5.44)\end{array}$ & 0.316 \\
\hline New PPI $(n, \%)$ & 75 (24.6) & $111(19.8)$ & $\begin{array}{l}0.79 \\
(0.59-1.05)\end{array}$ & 0.107 \\
\hline \multicolumn{5}{|l|}{ At 1 year ${ }^{b}$} \\
\hline $\begin{array}{l}\text { All-cause death (n, } \\
\% \text { ) }\end{array}$ & $42(13.7)$ & 69 (12.3) & $\begin{array}{l}0.88 \\
(0.60-1.29)\end{array}$ & 0.504 \\
\hline CV-death (n, \%) & $28(9.3)$ & $46(8.3)$ & $\begin{array}{l}0.88 \\
(0.55-1.41)\end{array}$ & 0.590 \\
\hline $\begin{array}{l}\text { Disabling stroke } \\
(\mathrm{n}, \%)\end{array}$ & $9(3.0)$ & $22(4.0)$ & $\begin{array}{l}1.33 \\
(0.61-2.89)\end{array}$ & 0.472 \\
\hline \multicolumn{5}{|l|}{ At 5 years ${ }^{c}$} \\
\hline $\begin{array}{l}\text { All-cause death (n, } \\
\%)\end{array}$ & $134(48.8)$ & $220(45.6)$ & $\begin{array}{l}0.89 \\
(0.72-1.10)\end{array}$ & 0.292 \\
\hline CV-death (n, \%) & $91(36.4)$ & $146(33.7)$ & $\begin{array}{l}0.87 \\
(0.67-1.13)\end{array}$ & 0.307 \\
\hline
\end{tabular}

Number of first events are presented (\% from life table estimate). Hazard ratios with $95 \%$ confidence interval CI reported.

$\mathrm{MAC}=$ mitral annular calcification, $\mathrm{HR}=$ hazard ratio, $\mathrm{CI}=$ confidence interval, $\mathrm{CV}$-death $=$ cardiovascular death, PPI $=$ permanent pacemaker implantation.

${ }^{\text {a }}$ Censored at death or otherwise at last valid contact up to 30 days.

b Censored at 365 days.

c Censored at death or otherwise at last valid contact.

MS in elderly patients with aortic stenosis. ${ }^{12}$ The score, however, is derived from non-contrast MDCT and therefore requires paired contrast-enhanced images to locate the exact region of the mitral annulus. ${ }^{13}$

The method adopted in our work has been well described for the aortic valve, ${ }^{14-17}$ but not yet applied to the MV. It allows to easily distinguish between different cardiac structures since MCV is measured on contrast-enhanced MDCT images using an individual cut-off derived from the actual luminal attenuation of the left heart chambers. In our study, this method showed excellent reproducibility and was consistent with conventional visual assessment of MAC severity. Further, an incremental value for the prediction of MS was observed and significant correlations were found between MCV and key echocardiographic parameters such as MVA, mean gradient, and pressure half-time. This is in

Table 2

Multivariable logistic regression analysis for the prediction of mitral stenosis.

\begin{tabular}{|c|c|c|c|c|}
\hline & \multicolumn{2}{|l|}{ Univariate Analysis } & \multicolumn{2}{|l|}{ Multivariate Analysis } \\
\hline & OR $(95 \% \mathrm{CI})$ & $P$ value & Adjusted OR (95\% CI) & $P$ value \\
\hline Anterior MCV $\geq 24.9 \mathrm{~mm}^{3}$ & $6.29(4.33-9.14)$ & $<0.001$ & $2.95(1.91-4.55)$ & $<0.001$ \\
\hline Posterior MCV $\geq 190.7 \mathrm{~mm}^{3}$ & $12.30(8.09-18.80)$ & $<0.001$ & $8.11(5.11-12.90)$ & $<0.001$ \\
\hline Age (years) & $1.02(0.99-1.05)$ & 0.243 & & \\
\hline Gender (female) & $2.11(1.46-3.04)$ & $<0.001$ & & \\
\hline Renal failure $(\mathrm{GFR}<60)$ & $1.34(0.92-1.96)$ & 0.130 & & \\
\hline Degenerative bioprosthetic valve & $0.93(0.31-2.75)$ & 0.892 & & \\
\hline AVA $\left(\mathrm{cm}^{2}\right)$ & $0.29(0.13-0.64)$ & 0.002 & $0.38(0.15-0.94)$ & 0.037 \\
\hline LVEF (\%) & $1.03(1.01-1.04)$ & $<0.001$ & $1.02(1.00-1.04)$ & 0.025 \\
\hline $\mathrm{AR}(\geq$ moderate $)$ & $0.97(0.55-1.71)$ & 0.913 & & \\
\hline
\end{tabular}

Multivariable logistic regression models include variables stepwise if the p-value of entry was $<0.1$.

Patients with missing data excluded.

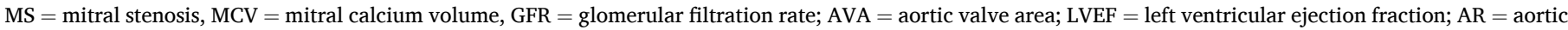
regurgitation; $\mathrm{OR}=$ odds ratio, $\mathrm{CI}=$ confidence interval. 
Table 4

Incremental effect of mitral calcium volume on clinical outcomes.

\begin{tabular}{|c|c|c|c|c|c|c|c|c|c|}
\hline & \multirow{3}{*}{$\begin{array}{l}\mathrm{MCV}= \\
0 \mathrm{~mm}^{3} \\
\mathrm{n}(\%)\end{array}$} & \multicolumn{4}{|c|}{$\operatorname{MCV}\left(\mathrm{mm}^{3}\right)$} & \multicolumn{4}{|l|}{ Hazard ratio } \\
\hline & & $\begin{array}{l}0.2-44.65 \\
\text { (A) } \\
\text { n (\%) }\end{array}$ & $\begin{array}{l}44.66-230.55 \\
\text { (B) } \mathrm{n}(\%)\end{array}$ & $\begin{array}{l}230.56-1023.55 \\
\text { (C) n (\%) }\end{array}$ & $\begin{array}{l}1023.56-10038.5 \\
\text { (D) } \mathrm{n}(\%)\end{array}$ & $\begin{array}{l}\text { (A) vs } \\
\mathrm{MCV}<0 \\
\mathrm{~mm}^{3}\end{array}$ & $\begin{array}{l}\text { (B) vs } \\
\mathrm{MCV}<0 \\
\mathrm{~mm}^{3}\end{array}$ & $\begin{array}{l}\text { (C) vs } \\
\mathrm{MCV}<0 \\
\mathrm{~mm}^{3}\end{array}$ & $\begin{array}{l}\text { (D) vs } \\
\mathrm{MCV}<0 \\
\mathrm{~mm}^{3}\end{array}$ \\
\hline & & & & & & $\begin{array}{l}\mathrm{HR}(95 \% \mathrm{CI}) \\
\text { P-value }\end{array}$ & $\begin{array}{l}\text { HR }(95 \% C I) \\
\text { P-value }\end{array}$ & $\begin{array}{l}\mathrm{HR}(95 \% \mathrm{CI}) \\
\text { P-value }\end{array}$ & $\begin{array}{l}\text { HR }(95 \% \mathrm{CI}) \\
\text { P-value }\end{array}$ \\
\hline $\begin{array}{l}\text { Permanent } \\
\text { pacemaker } \\
\text { implantation ( } 30 \\
{\text { days })^{\mathrm{a}}}^{\text {a }}\end{array}$ & $\begin{array}{l}75 \\
(24.6)\end{array}$ & 25 (17.6) & $26(18.5)$ & $31(22.3)$ & 29 (20.9) & $\begin{array}{l}0.68 \\
(0.43-1.07) \\
P=0.099\end{array}$ & $\begin{array}{l}0.74 \\
(0.47-1.15) \\
P=0.177\end{array}$ & $\begin{array}{l}0.89 \\
(0.59-1.36) \\
P=0.601\end{array}$ & $\begin{array}{l}0.84 \\
(0.55-1.29) \\
P=0.420\end{array}$ \\
\hline $\begin{array}{l}\text { Cardiovascular } \\
\text { death }(1 \text { year })^{\mathrm{b}}\end{array}$ & $28(9.3)$ & $12(8.6)$ & $10(7.2)$ & $6(4.3)$ & $18(13.2)$ & $\begin{array}{l}0.91 \\
(0.46-1.79) \\
\mathrm{P}=0.782\end{array}$ & $\begin{array}{l}0.76 \\
(0.37-1.57) \\
P=0.460\end{array}$ & $\begin{array}{l}0.45 \\
(0.19-1.09) \\
P=0.076\end{array}$ & $\begin{array}{l}1.42 \\
(0.78-2.56) \\
P=0.248\end{array}$ \\
\hline $\begin{array}{l}\text { Cardiovascular } \\
{\text { death }(5 \text { year })^{\mathrm{c}}}^{\text {Sensitivity analysis }}\end{array}$ & $\begin{array}{l}91 \\
(36.4)\end{array}$ & $27(26.0)$ & $40(37.6)$ & $35(33.4)$ & $44(36.2)$ & $\begin{array}{l}0.68 \\
(0.44-1.05) \\
P=0.080\end{array}$ & $\begin{array}{l}0.94 \\
(0.65-1.37) \\
P=0.753\end{array}$ & $\begin{array}{l}0.79 \\
(0.53-1.16) \\
P=0.224\end{array}$ & $\begin{array}{l}1.08 \\
(0.75-1.55) \\
P=0.673\end{array}$ \\
\hline $\begin{array}{l}\text { Permanent } \\
\text { pacemaker } \\
\text { implantation ( } 30 \\
\text { days) })^{\mathrm{a}}\end{array}$ & $\begin{array}{l}57 \\
(25.8)\end{array}$ & $17(15.9)$ & $18(17.8)$ & $24(24.5)$ & $21(22.8)$ & $\begin{array}{l}0.58 \\
(0.34-1.00) \\
P=0.051\end{array}$ & $\begin{array}{l}0.67 \\
(0.39-1.13) \\
P=0.134\end{array}$ & $\begin{array}{l}0.95 \\
(0.59-1.52) \\
P=0.819\end{array}$ & $\begin{array}{l}0.89 \\
(0.54-1.46) \\
P=0.636\end{array}$ \\
\hline
\end{tabular}

Number of first events are presented (\% from life table estimate). Hazard ratios with 95\% confidence interval CI reported.

MCV: mitral calcium volume, $\mathrm{RR}=$ rate ratio, $\mathrm{HR}=$ hazard ratio, $\mathrm{CI}=$ confidence interval.

a Censored at death or otherwise at last valid contact up to 30 days.

b Censored at 365 days.

c Censored at death or otherwise at last valid contact.

${ }^{\mathrm{d}}$ Excluded patients with previous pacemaker, cardioverter-defibrillator, right bundle branch block, atrio-ventricular block at baseline.

line with previous findings obtained using echocardiography. ${ }^{20-24}$ MAC has been occasionally described to cause or worsen MR in echocardiographic studies. ${ }^{1,10,26-29}$ However, in our analysis and the study by Eberhard et al. using the Agatston score, ${ }^{12}$ MAC did not predict the occurrence of MR that rather seems to develop incidentally.

Not only the severity but also the location of mitral calcium may affect MV function. ${ }^{1,10,30,31}$ Although calcification is more frequently located at the posterior aspect of annulus and leaflets, authors have suggested a greater impact of anterior calcium deposits on MV function. ${ }^{11}$ In our analysis, both anterior and posterior MCV independently predicted the presence of MS, whereas posterior MCV had a higher predictive value. Importantly, patients with anterior MCV had a higher total MCV than those without, suggesting more advanced disease. In some patients, MV function was not affected even in the presence of high MCV or visually severe MAC. As illustrated in Fig. 6, this may be explained by predominant annular or myocardial involvement without leaflet disease. Although the differentiation of leaflet and annular calcification was not systematically performed in the present study, a sub-analysis of the 37 patients with relevant MS revealed that all had calcification extending to the mid-portion of the leaflets, and 19 (51\%) even to the tip.

In contrast to previous studies, ${ }^{2,5-8,13}$ our work found no effect of mitral calcium on clinical outcomes including cardiovascular death and new PPI following TAVI, corroborating our previous work. ${ }^{9}$ There are several possible explanations for these results. First, older age and higher prevalence of comorbidities in TAVI patients might attenuate the clinical impact of mitral calcium. Second, patients with prognostically relevant MV disease may have been selected for surgery rather than TAVI. Therefore, the analysis in TAVI candidates may underestimate the prognostic impact of mitral calcium associated with MV dysfunction. ${ }^{9,34}$ Third, LVOT calcification, which has been excluded from our analysis, may have acted as a confounder when using visual assessment only. ${ }^{7}$ Indeed, LVOT calcium has been described as a predictor of new PPI following TAVI. ${ }^{32}$ In another retrospective analysis including 136 subjects, patients who required new PPI had a higher prevalence of aortomitral continuity calcification, while the prevalence of aortic valve and mitral annular calcification were similar compared to patients without new PPI. ${ }^{33}$ On the other hand, the study by Brodov et al. showed a significant association between MAC and new conduction abnormalities after excluding LVOT calcification by using paired contrast-enhanced images. ${ }^{13}$ One hypothesis might be that mitral caseous necrosis, which is identified by the Agatston method but not by our technique due to similar attenuation values with intra-vascular contrast, could be a contributor to the risk of procedural complication. ${ }^{25}$ The association between mitral calcium and new conduction abnormalities needs cautious interpretation given the multifactorial mechanisms involved, such as the topographic anatomy of the conduction system, the length of the membranous septum, pre-existing right bundle branch block, the type and size of the implanted prosthesis, and the implantation depth. ${ }^{32}$ Moreover, the indication of new PPI may vary among institutions. Therefore, further investigations are certainly needed to clarify the impact of mitral calcification on clinical outcomes in TAVI patients, as well as in other clinical settings.

\subsection{Study limitations}

Our study has several limitations. First, the studied cohort was limited to TAVI candidates and findings may not be transferable to other populations. Second, the exclusive inclusion of patients with adequate echocardiographic and MDCT assessment may have introduced an unintended selection bias. Third, imaging quality and protocols have been changed over time as shown in the supplemental information, which may have affected MCV analysis. Finally, in the present analysis, total as well as anterior and posterior MCV were measured without distinction between leaflet and annular calcium.

\subsection{Conclusions and clinical implications}

Calcification of the mitral annulus is common in TAVI candidates and result in MS in one quarter of the patients. The identification of calcifications of the mitral apparatus on pre-procedural MDCT should prompt careful and integrative echocardiographic assessment of mitral 


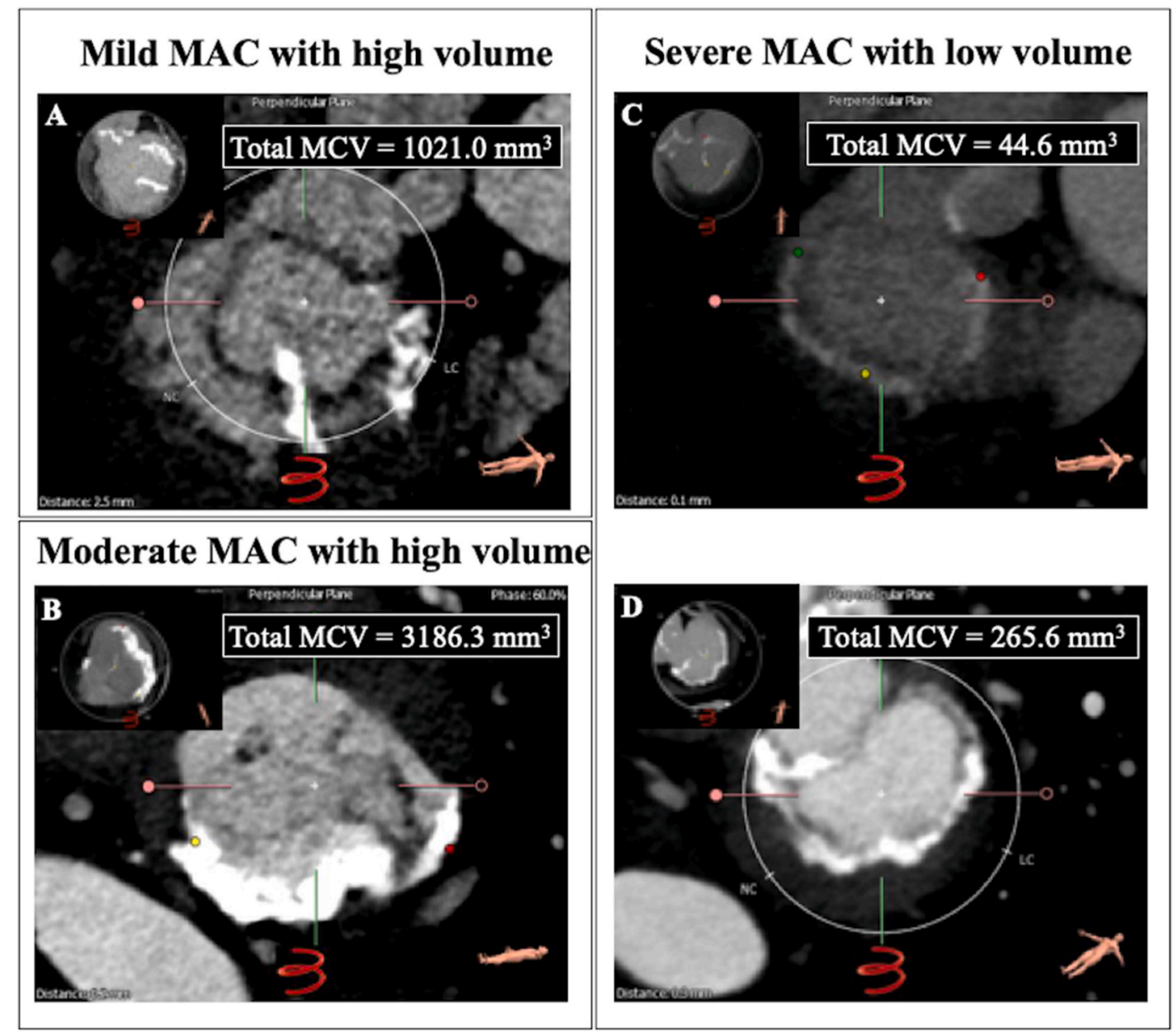

Fig. 5. Examples of discrepancies between visual mitral annular calcification severity and mitral calcium volume

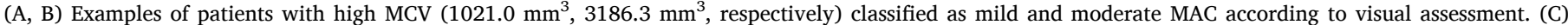

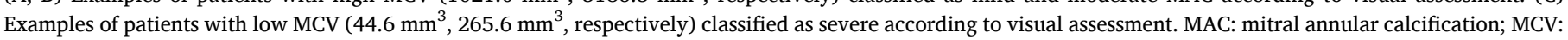
mitral calcium volume.

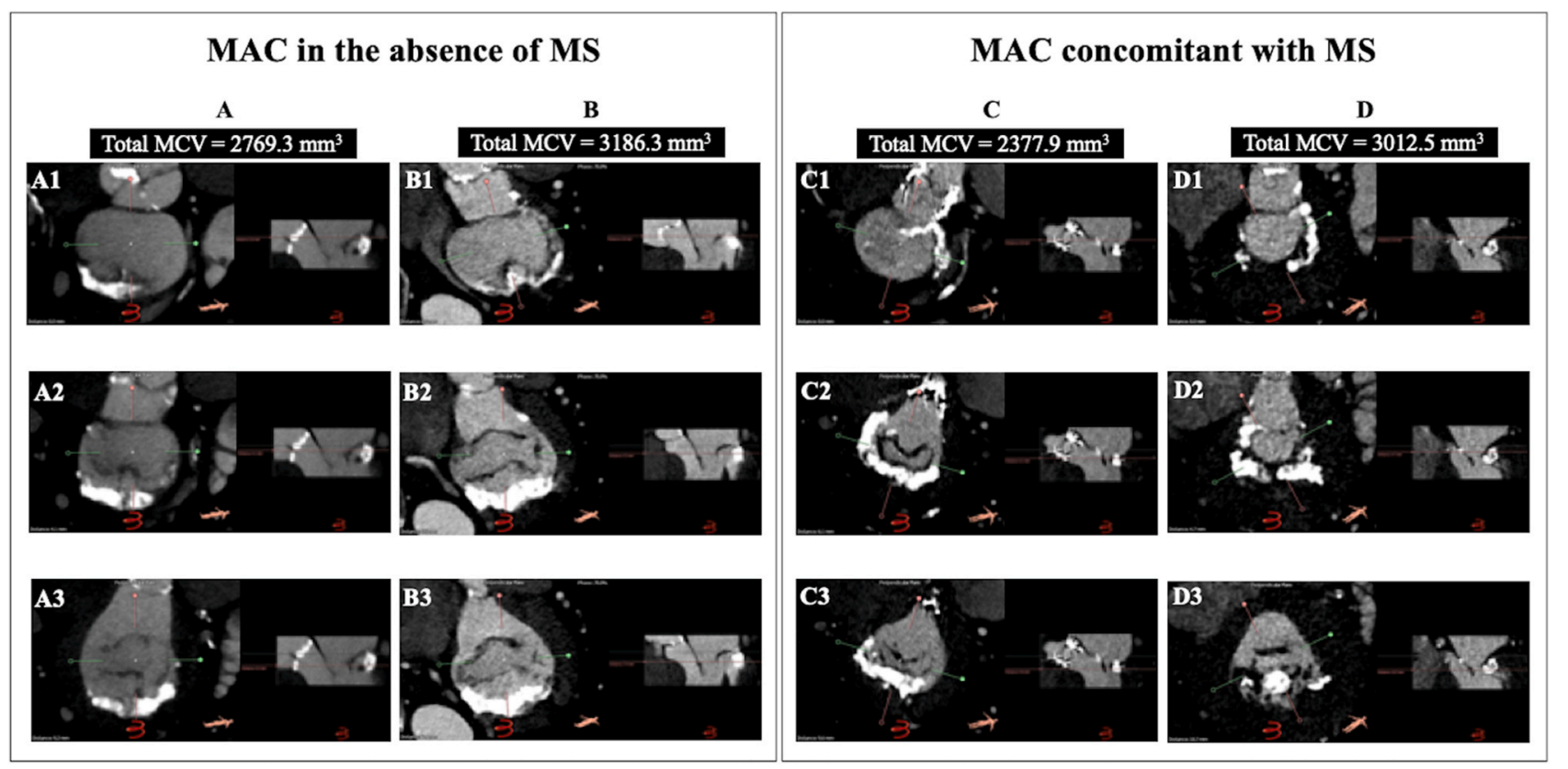

Fig. 6. Examples of patients with high mitral calcium volume with/without mitral stenosis.

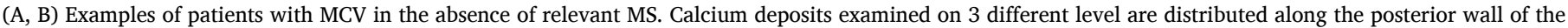

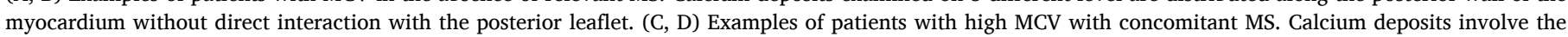
posterior leaflets. MAC: mitral annular calcification; MCV: mitral calcium volume; MS: mitral stenosis 
valve function to detect MS, which is associated with impaired prognosis following TAVI. ${ }^{34}$ Our work first provide MCV cut-offs helping to identify patients with MS based on pre-procedural MDCT. MCV may be a more accurate assessment of mitral calcification than the conventional visual MAC classification, but had no impact on clinical outcomes up to 5 years after TAVI.

\section{Funding}

None.

\section{Disclosure}

Dr. Windecker reports research and educational grants to the institution from Abbott, Amgen, BMS, Bayer, Boston Scientific, Biotronik, Cardinal Health, CardioValve, CSL Behring, Daiichi Sankyo, Edwards Lifesciences, Johnson\&Johnson, Medtronic, Querbet, Polares, Sanofi, Terumo, Sinomed. S. Windecker serves as unpaid member of the steering/excecutive group of trials funded by Abbott, Abiomed, Amgen, BMS, Boston Scientific, Biotronik, Cardiovalve, Edwards Lifesciences, MedAlliance, Medtronic, Polares, Sinomed, V-Wave and Xeltis, but has not received personal payments by any pharmaceutical company or device manufacturer. He is also member of the steering/excecutive committee group of several investigated-initiated trials that receive funding by industry without impact on his personal remuneration. Dr. Kodali reports having received research grants to the institution from Edwards Lifesciences, Medtronic, Boston Scientific, and Abbott, and consulting fees from Abbott, Claret Medical, Admedus, and Meril Lifesciences, and has served on the Scientific Advisory Boards of Biotrace Medical, Dura Biotech, and Thubrikar Aortic Valve Inc. Dr. George reports having received consulting fees from Edwards Lifesciences, and institutional research support from Edwards Lifesciences. Dr. Pilgrim reports having received research grants to the institution from Symetis/Boston Scientific, and Biotronik, and speaker fees from Boston Scientific and Biotronik, and consultancy from HighLife SAS. Dr. KodaliDr. Stortecky reports having received research grants to the institution by Edwards Lifesciences, Medtronic, Abbott, and Boston Scientific, and speaker fees from Boston Scientific, Teleflex, and BTG. Dr. Okuno reports having received speaker fees from Abbott. Dr. Khalique has received speaker's fees from Edwards Lifesciences, and is a consultant for Abbott Structural and Boston Scientific. (All conflicts are "modest") Dr. Praz has received travel expenses from Edwards Lifesciences, Abbott Medical, and Polares Medical. All other authors have no relationships relevant to the contents of this article to disclose.

\section{Acknowledgements}

None.

\section{Appendix A. Supplementary data}

Supplementary data to this article can be found online at https://doi. org/10.1016/j.jcct.2020.10.003.

\section{References}

1. Abramowitz Y, Jilaihawi H, Chakravarty T, Mack MJ, Makkar RR. Mitral annulus calcification. J Am Coll Cardiol. 2015;66:1934-1941.

2. Kanjanauthai S, Nasir K, Katz R, et al. Relationships of mitral annular calcification to cardiovascular risk factors: the Multi-Ethnic Study of Atherosclerosis (MESA). Atherosclerosis. 2010;213:558-562.

3. Foley PW, Hamaad A, El-Gendi H, Leyva F. Incidental cardiac findings on computed tomography imaging of the thorax. BMC Res Notes. 2010;3:326.

4. Fox Caroline S, Vasan Ramachandran S, Parise H, et al. Mitral annular calcification predicts cardiovascular morbidity and mortality. Circulation. 2003;107:1492-1496.
5. Völzke H, Haring R, Lorbeer R, et al. Heart valve sclerosis predicts all-cause and cardiovascular mortality. Atherosclerosis. 2010;209:606-610.

6. Kohsaka S, Jin Z, Rundek T, et al. Impact of mitral annular calcification on cardiovascular events in a multiethnic community: the Northern Manhattan Study. J Am Coll Cardiol Img. 2008;1:617-623.

7. Abramowitz Y, Kazuno Y, Chakravarty T, et al. Concomitant mitral annular calcification and severe aortic stenosis: prevalence, characteristics and outcome following transcatheter aortic valve replacement. Eur Heart J. 2017;38:1194-1203.

8. Ancona MB, Giannini F, Mangieri A, et al. Impact of mitral annular calcium on outcomes after transcatheter aortic valve implantation. Am J Cardiol. 2017;120: 2233-2240.

9. Okuno T, Asami M, Khan F, et al. Does isolated mitral annular calcification in the absence of mitral valve disease affect clinical outcomes after transcatheter aortic valve replacement? Eur Heart J Cardiovasc Imag. 2020;21:522-532.

10. Eleid MF, Foley TA, Said SM, Pislaru SV, Rihal CS. Severe mitral annular calcification: multimodality imaging for therapeutic strategies and interventions. J Am Coll Cardiol Img. 2016;9:1318-1337.

11. Mejean S, Bouvier E, Bataille V, et al. Mitral annular calcium and mitral stenosis determined by multidetector computed tomography in patients referred for aortic stenosis. Am J Cardiol. 2016;118:1251-1257.

12. Eberhard M, Schonenberger ALN, Hinzpeter R, et al. Mitral annular calcification in the elderly - quantitative assessment. J Cardiovasc Comput Tomogr; 2020. https://do i.org/10.1016/j.jcct.2020.06.001.

13. Brodov Y, Konen E, Di Segni M, et al. Mitral annulus calcium score. Circ Cardiovasc Imag. 2019;12, e007508.

14. Jilaihawi H, Makkar RR, Kashif M, et al. A revised methodology for aortic-valvar complex calcium quantification for transcatheter aortic valve implantation. Eur Heart J Cardiovasc Imag. 2014;15:1324-1332.

15. Alqahtani AM, Boczar KE, Kansal V, Chan K, Dwivedi G, Chow BJ. Quantifying aortic valve calcification using coronary computed tomography angiography. J Cardiovasc Comput Tomogr. 2017;11:99-104.

16. Khalique OK, Hahn RT, Gada H, et al. Quantity and location of aortic valve complex calcification predicts severity and location of paravalvular regurgitation and frequency of post-dilation after balloon-expandable transcatheter aortic valve replacement. J Am Coll Cardiol Intv. 2014;7:885-894.

17. Bettinger N, Khalique OK, Krepp JM, et al. Practical determination of aortic valve calcium volume score on contrast-enhanced computed tomography prior to transcatheter aortic valve replacement and impact on paravalvular regurgitation: elucidating optimal threshold cutoffs. J Cardiovasc Comput Tomogr. 2017;11: 302-308.

18. Stortecky S, Franzone A, Heg D, et al. Temporal trends in adoption and outcomes of transcatheter aortic valve implantation: a swisstavi registry analysis. Eur Heart J Qual Care Clin Outcomes. 2019;5:242-251.

19. Lancellotti P, Tribouilloy C, Hagendorff A, et al. Zamorano JL and on behalf of the scientific document committee of the European association of cardiovascular imaging: thor edvardsen OBBCEDRDMGPLDMK. Eur Heart J Cardiovasc Imag. 2013; 14:611-644.

20. Baumgartner H, Hung $J$, Bermejo J, et al. Echocardiographic assessment of valve stenosis: EAE/ASE recommendations for clinical practice. Eur J Echocardiogr. 2009; $10: 1-25$.

21. Kappetein AP, Head SJ, Genereux P, et al. Updated standardized endpoint definitions for transcatheter aortic valve implantation: the Valve Academic Research Consortium-2 consensus document (VARC-2). Eur J Cardio Thorac Surg. 2012;42: S45-S60.

22. Praz F, Khalique OK, Lee R, et al. Transatrial implantation of a transcatheter heart valve for severe mitral annular calcification. J Thorac Cardiovasc Surg. 2018;156: $132-142$.

23. Guerrero M, Urena M, Himbert D, et al. 1-Year outcomes of transcatheter mitral valve replacement in patients with severe mitral annular calcification. J Am Coll Cardiol. 2018;71:1841-1853.

24. Sorajja P, Gossl M, Babaliaros V, et al. Novel transcatheter mitral valve prosthesis for patients with severe mitral annular calcification. J Am Coll Cardiol. 2019;74: 1431-1440.

25. Agatston AS, Janowitz WR, Hildner FJ, Zusmer NR, Viamonte Jr M, Detrano R. Quantification of coronary artery calcium using ultrafast computed tomography. J Am Coll Cardiol. 1990;15:827-832.

26. Nestico PF, Depace NL, Morganroth J, Kotler MN, Ross J. Mitral annular calcification: clinical, pathophysiology, and echocardiographic review. Am Heart J. 1984;107:989-996.

27. Movahed MR, Saito Y, Ahmadi-Kashani M, Ebrahimi R. Mitral annulus calcification is associated with valvular and cardiac structural abnormalities. Cardiovasc Ultrasound. 2007;5:14.

28. Labovitz AJ, Nelson JG, Windhorst DM, Kennedy HL, Williams GA. Frequency of mitral valve dysfunction from mitral annular calcium as detected by Doppler echocardiography. Am J Cardiol. 1985;55:133-137.

29. Zemer Wassercug N, Shapira Y, Weisenberg D, et al. Association between mitral annular calcium and flail mitral leaflet in degenerative mitral valve disease. Am J Cardiol. 2015;116:121-124.

30. Mahnken AH, Muhlenbruch G, Das M, et al. MDCT detection of mitral valve calcification: prevalence and clinical relevance compared with echocardiography. AJR Am J Roentgenol. 2007;188:1264-1269. 
31. Movva R, Murthy K, Romero-Corral A, Seetha Rammohan HR, Fumo P, Pressman GS. Calcification of the mitral valve and annulus: systematic evaluation of effects on valve anatomy and function. Am Soc Echocardiogr. 2013;26:1135-1142.

32. Maeno Y, Abramowitz Y, Kawamori H, et al. A highly predictive risk model for pacemaker implantation after TAVR. J Am Coll Cardiol Img. 2017;10:1139-1147.
33. Katchi F, Bhatt D, Markowitz SM, et al. Impact of aortomitral continuity calcification on need for permanent pacemaker after transcatheter aortic valve replacement. Circ Cardiovasc Imag. 2019;12, e009570.

34. Asami M, Windecker S, Praz F, et al. Transcatheter aortic valve replacement in patients with concomitant mitral stenosis. Eur Heart J. 2019;40:1342-1351. 